\title{
The optimal structure of lotto games
}

\author{
O. David Gulley* \\ Department of Economics, Bentley University, Waltham, US
}

Received: 30 July 2018

Revised: 9 November 2018

Accepted: 9 November 2018

\begin{abstract}
Operators of state-owned lottery games generally attempt to set the parameters of the game(s) to maximize revenue to the state. This paper discusses the state of the literature on how to set the parameters of a lotto game so as to accomplish this objective.
\end{abstract}

Keywords: lotto; lottery

JEL Classification Codes: $\mathrm{H} 7$

\section{Introduction}

Operators of state-owned lotto games generally attempt to set the parameters of the game(s) to maximize revenue to the state. Parameters include the nominal price of the lotto ticket, probability of winning the jackpot, the monetary value of the various prizes, and the overall payout rate (the fraction of wagers returned as prizes). In turn, these parameters determine the expected value, variance, and skewness of the lotto game. Most lottery operators present bettors with a portfolio of games to appeal varying to preferences for the parameters listed, as well as others, such as willingness to wait (or not) for a prize, frequency of play opportunities, etc. In setting the parameters, game operators face a number of constraints, including competition from other forms of gambling (or entertainment in general), the overall state of the economy, and bettor preferences, among others.

This paper focuses on the state of the literature for setting the parameters of a lotto game so as to accomplish the operator's objective. While each parameter is addressed in turn, it is important to note that these are usually determined jointly.

\section{Ticket price}

Lotto tickets are generally priced in small, round units of the local currency to make purchase as convenient as possible. Nominal lotto ticket prices do not change very often. In the U.S.,

\footnotetext{
*E-mail: dgulley@bentley.edu.

Citation: Gulley, O. D. (2018) The optimal structure of lotto games, Economics and Business Letters, 7(4), 156161.
} 
most state lotto games are priced at $\$ 1$ and have been so for years. Changing ticket prices carries risk to the operator. Raising the price may put off many buyers to the extent that sales are price elastic. If sales are relatively inelastic, however, then revenue may of course increase. Raising the ticket price also impacts the jackpot in several ways. First, if ticket sales are inelastic, the increase in sales revenue will translate into larger jackpots because a fraction of sales is dedicated to the jackpot. Second, regardless of the elasticity of demand, any decrease in ticket sales increases the likelihood of a rollover, which will work to further increase jackpots. Three particular cases are of interest here. Beenstock and Haitovsky (2001) examine a number of structural changes to the Israeli lotto game, including changes to the nominal ticket price, which was raised over a dozen times in the 1984-1997 period. The initial half-dozen nominal increases approximately doubled the real price. Subsequent increases were intended to stabilize the real price in the face of double-digit inflation. Given that many other parameters of the Israeli lotto game were being changed over their sample period, it is difficult to pin down the impact of the change in ticket prices on sale revenue. Still, over their sample period, real sales saw a slight upward trend, unlike lotto games in many other countries. Forrest and Perez (2011) examine a Spanish lotto game. In September 2002, the nominal entry fee was raised from 60 to 90 eurocents. Comparing the number of tickets sold in the twelve months before and after the change, there was a fall of only $10 \%$, yielding a substantial increase in revenue. A further rise to $€ 1$ per ticket in September, 2004 was followed by a modest decline in number of tickets sold. In short, the demand was relatively ticket price inelastic. In contrast, Forrest and Gulley (2018a) examine the UK National Lottery main lotto game that doubled the price of a ticket from $£ 1$ to $£ 2$ in October 2013 in an attempt to increase revenue that had been steadily declining for years ${ }^{1}$. The operator was betting on some combination of a relatively inelastic ticket price demand and/or an increase in the number of rollovers causing larger jackpots to induce more playing. The authors find that while these changes increased revenue to a level higher than it likely would have been without the changes, the underlying downward trend in sales revenue was not slowed.

\section{Odds of winning the jackpot}

The parameter of interest here is the "size" of the lotto game. A typical game is a 6/49 setup where the jackpot is won matching all six numbers in any order. Smaller prizes are usually paid for matching between three and five numbers. What are the right odds of winning the jackpot? Making it too easy to win the jackpot leads to very few rollovers, which are capable of driving high sales revenue. If the jackpot is too hard to win, repeated rollovers may drive away bettors. Cook and Clotfelter (1993) analyze the product of the probability of winning the jackpot in a state with its population and find that the product seems to be around one for most states. Whether this was consciously chosen across states is not known. It is interesting to point out that both the multistate Megamillions and Powerball games in the U.S. recently lengthened the odds of winning the jackpots and the result is that the product of the probability of winning the jackpot and the U.S. population is fairly close to one. The subsequently larger jackpots produced publicity and strong sales.

The UK National Lotto, after having doubled the ticket price in October 2013, made even more changes to the game in October 2015 in an attempt to reverse the continued drop in sales. Changes included making all cash prizes in the game much harder to win and adding the prize of a free lotto ticket for matching two numbers out of six. The underlying downward sales decline was not reversed and there was no bump in revenue similar to the October 2013 changes even though the product of the odds of winning the jackpot and the UK population became much closer to one than in the previous structure. Forrest and Gulley (2018b) find that bettors

\footnotetext{
${ }^{1}$ There were some relatively minor changes to the payout structure of the game as well, along with the addition of a number of $£ 20,000$ raffle prizes.
} 
generally became less sensitive to jackpot size.

The odds of winning the main jackpot are of course critical to predicting how frequently the lotto game will be rolled over. Some lotto games feature limits to the number of times the jackpot can rollover or the maximum size of the jackpot. Limits may be imposed to prevent too much time passing between jackpot wins, which might reduce player interest. Once the maximum number of rollovers is achieved or the jackpot maximum is reached, if the grand prize is not won on the subsequent drawing, then the jackpot value "rolls down" to the next prize tier and is typically split among those holding winning tickets. The next lowest prize tier in lotto games is usually easy enough to win such that there is virtually guaranteed to be at least one winner ${ }^{2}$. The incentive is for bettors to wait until these maximums are reached to place wagers. In other words, lottery operators that cap jackpots in some manner are training their players to wait until the jackpots are at the highest levels. For example, the UK Lotto has gone through a variety of jackpot/rollover limits with a trend toward reducing the length of the rollover cycle. In the most recent change, from November 2018 onward, the number of rollovers will be capped at five. If the jackpot is not won on the fifth rollover drawing, the value of the jackpot will be distributed (rolled down) to lower prize tiers of that drawing ${ }^{3}$. Previously, once the jackpot hit $£ 22$ million, if the jackpot was not won on the subsequent drawing, it was rolled down to the next prize tier. Based on recent sales figures, the new regime will yield smaller maximum jackpots. Forrest and Gulley (2018b) find that such caps are associated with a higher level of play on the roll-down drawing.

\section{Price payout rate}

The next parameter is the takeout rate, the fraction of revenue not returned to bettors as prizes. The average level is around $50 \%$, though there is variation across operators. It is difficult to discover the optimal payout rate for lotto games because operators rarely change the payout rate and so empirical evidence is hard to come by. Instead, researchers have conducted detailed simulations about the optimal payout rate. Walker and Young (2001) find some evidence that revenue for the UK National Lotto could be increased by raising the takeout rate. Hartley and Lanot (2003) find evidence to support the opposite result: the takeout rate is too high. It is important to point out here that Walker and Young (2001) suggest that using rollover-induced effective price changes is, at best, a very imperfect way to infer how structural changes may affect bettor behavior, at least in part due to the ability of bettors to engage in intertemporal substitution across drawings offering better expected payoffs. Beenstock and Haitovsky (2001) examine the Israeli lottery and note that the payout rate was increased from $50 \%$ to $55 \%$ over the period 1993 to 1996. Combined with the ticket price changes discussed above and making the jackpot harder to win have lead, collectively, to larger jackpots and increased sales. It is difficult to pinpoint which, if any, of these changes has been more important than the others, though the authors find evidence that the larger jackpots from the longer odds (and perhaps higher ticket prices) have had the largest impact on sales.

\section{Distribution of prices}

It is not unreasonable to assume that lotto players play for the chance of winning the jackpot ${ }^{4}$. Still, all lotto games offer smaller prizes for matching some subset of the jackpot-winning number combination to maintain bettor interest; otherwise, players would surely fall away as they

\footnotetext{
${ }^{2}$ The roll-down of the jackpot can instances where the expected value of a lotto ticket becomes well more than the purchase price of a ticket. See for example: https://highline.huffingtonpost.com/articles/en/lotto-winners/.

${ }^{3}$ For a summary of the November 2018 changes, see https://www.national-lottery.com/national-lottery-changes/.

${ }^{4}$ Forrest, Simmons, and Chesters (2002) find that jackpots outperform the expected value of a lotto ticket as an explanatory variable of lotto sales. The expected value of a ticket includes smaller prizes.
} 
never won anything. How should prizes be split up? In other words, how much of the expected value of a ticket should go towards the jackpot and how much to smaller prizes, and thus, how skewed should payouts be?

Quiggin (1991) developed a model suggesting that the optimal structure of a lotto game should feature a large prize (or maybe a few) and many smaller prizes, suggesting a relatively high level of skewness. Garrett and Sobel (1999) find that across all state lotto games as of 1995 , bettors act as if they are risk averse and skewness seeking in that there is a preference of prizes skewed toward the jackpot.

Lottery operators have also experimented with changing the structure of the games to influence skewness with mixed success. Megamillions and Powerball, the multi-state games in the US, both doubled ticket prices and lengthened the odds of winning the main jackpot, increasing the skewness of the games. Rollovers have increased resulting in periodic jackpots over $\$ 400$ million. Sales revenue has increased.

Walker (1998) simulates the impact on sales of the UK National Lottery of various odds of winning the jackpot and concludes that a 6/59 game, for example, would substantially reduce sales, foretelling the actual decline in sales post-2015 as discussed above.

There are two caveats here. First, as noted above, Walker and Young (2001) are skeptical of using rollover-induced effective price changes to infer how structural changes may affect bettor behavior. Second, results of a structural change in one jurisdiction may be a poor guide to how like changes in another jurisdiction may work. The changes made to the Megamillions and Powerball games seemed to work well for the operators. The Spanish National Lottery operator made major changes to the structure of one of its three games in 2005. The jackpot was made much more difficult to win, lower tier prizes were increased, and a relatively large minimum jackpot was introduced. Forrest, Perez, and Baker (2010) find that these changes were associated with increased sales revenue. In contrast, the October 2013 and October 2015 changes made to the UK lotto game discussed above have not worked out nearly as well.

\section{The optimal lottery game portfolio and profit maximization}

It is important to consider how a given lotto game offered by an operator fits into the portfolio of lottery games offered. In many jurisdictions, a variety of games are offered appealing to differing bettor preferences across a number of parameters, including the size of the jackpot, skewness of the game, draw frequency, length of time to wait for a potential payout, and so forth. Consider the case of Massachusetts, which has long had the most successful lottery in the US when measured on a per-capita sales basis. While at least a portion of the high per capita sales can be explained by favorable demographic characteristics (a high population density, for example), some success is certainly attributable to game structures. The average payout to Massachusetts lottery players across all offerings is about $70 \%$, notably higher than the typical $50 \%$ in other jurisdictions. The state also offers a wide ranging portfolio from keno (with many daily drawings), a daily numbers game, several in-state lotto games, a multi-state game that pays out a life-time annuity to the grand prize winners, and two multistate lotto games (Megamillions and Powerball) $)^{5}$. The clear intent is to appeal to the widest possible spectrum of players in terms of their various preferences.

It is of course of critical importance to design the portfolio of games to minimize competition across games. For example, Forrest, Perez, and Baker (2010) find little evidence that the three Spanish lotto games are substitutes, implying that the games have appealed to different segments of the lotto-playing population. Forrest and MacHale (2006) find similar results for the UK National Lottery game and the Euromillions, a multi-nation lotto game. Lin and Lai (2006)

\footnotetext{
${ }^{5}$ There are also numerous scratchcard (instant) games running at any one time.
} 
find that the two lotto games in Taiwan are not substitutes or complements ${ }^{6}$. Forrest, Gulley, and Simmons (2004) on the other hand, find evidence that the offerings of the UK National lottery are to some degree substitutes. Matheson and Grote (2006) find that for their sample of state-level lotto games, the introduction of a multi-state lotto game tends to reduce sales revenue of the state-level games. However, they find that overall, sales of the state-level and multi-state games are complements. Stover (1990) shows that bettors are willing to cross state borders when the lotto game of a neighboring state offers a high jackpot. Knight and Schiff (2012) find similar results in states not offering one of the multi-state games.

Finally, have operators been successful at setting the various game parameters so as to maximize profits? The general answer, at least of the studies examining the issue, finds that the answer is in the vicinity of "yes." Gulley and Scott (1993), Forrest, Gulley, and Simmons (2000), and Perez and Forrest (2010) all examine this question for a variety of lotto games. These papers estimate the price elasticity of demand, and find that it is a little less than minus one for a number of lotto games, implying revenue maximization net of operating costs. The implication is that the operators studied have set game parameters appropriately. See also the citations in Grote and Matheson (2011) for additional discussion.

\section{Acknowledgements}

I would like to thank an anonymous referee for very helpful comments on an earlier version.

\section{References}

Beenstock, M., and Haitovsky, Y. (2001) Lottomania and other anomalies in the market for lotto, Journal of Economic Psychology, 22 (6), 721-744.

Cook, P. J., and Clotfelter, C. T. (1993) The peculiar scale economies of lotto, The_American Economic Review, 83(3), 634-643.

Forrest, D., and Gulley, O. D. (2018a) New price, new hope? an examination of the effects of doubling the ticket price in UK lotto, Journal of Gambling Studies, 34(1), 39-53.

Forrest, D., and Gulley, O. D. (2018b) Lengthening the odds: The effect on sales of making a lotto game harder to win, Working Paper. Waltham, MA

Forrest, D., Gulley, O. D., and Simmons, R. (2004) Substitution between Games in the UK National Lottery, Applied Economics, 36(7), 645-651.

Forrest, D., Simmons, R., and Chesters, N. (2002) Buying a dream: alternative models of demand for lotto, Economic Inquiry, 40(3), 485-496.

Forrest, D., and McHale, I. (2007) The relationship between a national and a multistate lotto game, Journal of Gambling Business and Economics, 1(3), 207-216.

Forrest, D., and Perez, L. (2011) Own and cross-price elasticities for games within a state lottery portfolio, Contemporary Economic Policy, 29(4), 536-549.

Forrest, D., Perez, L., and Baker, R. (2010) Evaluating the effects of game design on lotto sales: a case study from Spain, Journal of Gambling Business and Economics, 4(2), 1-20.

Garret, T. A., and Sobel, R.S. (1999) Gamblers favor skewness, not risk: further evidence from United States' lottery games, Economics Letters, 63(1), 85-90.

Grote, K. R., and Matheson, V. A. (2006) Dueling jackpots: are competing lotto games complements or substitutes?, Atlantic Economic Journal, 34(1), 85-100.

Grote, K. R., and Matheson, V. A. (2011) The economics of lotteries: a survey of the literature, Working Paper 16. Worcester, MA.

\footnotetext{
${ }^{6}$ Evidence of intertemporal substitution within a lotto game across low vs. high jackpot drawings has also been found. See Forrest, Gulley, and Simmons (2004).
} 
Gulley, O. D., and Scott Jr., F. A. (1993) The demand for wagering on state-operated lotto games, National Tax Journal, 46(1), 13-22.

Hartley, R., and Lanot, G. (2003) On the design of lottery games, Journal of the Operational Research Society, 54(1), 89-100.

Knight, B,. and Schiff, N. (2012) Spatial competition and cross-border shopping: evidence from state lotteries, American Economic Journal: Economic Policy, 4(4), 199-229.

Lin, C., and Lai, C. (2006) Substitute effects between lotto and big lotto in Taiwan, Applied Economics Letters, 13(10), 655-658.

Quiggin, J. (1991) On the optimal design of lotteries, Economica, 58(22), 1-16.

Stover, M. E. (1990) Contiguous state lotteries: substitutes or complements?, Journal of Policy Analysis and Management, 9(4), 565-568.

Walker, I. (1998) The economic analysis of lotteries, Economic Policy, 13(27), 359-92.

Walker, I., and Young, J. (2001) An economist's guide to lottery design, Economic Journal, 111(475), 700-722. 